\title{
AI BASED EXPERT SYSTEM FOR PREDICTION OF DIABETIC EYE MORBIDITY
}

\section{Himal Chitara \\ Dr. Hitesh Gilder*}

M.tech in Biomedical Engineering, U. V. Patel College of Engineering, Ganpat University, Gujarat

MS.(Ophthalmology), DO, DNB, Ophthalmology, Vivekand Eye Care Hospital, Rajkot *Corresponding Author

Assistant Professor in Biomedical Engineering, U. V. Patel College of Engineering, Ganpat University, Gujarat.

Assistant Professor in Biomedical Engineering, U. V. Patel College of Engineering, Ganpat University, Gujarat.

ABSTRACT Aim: to design an AI based expert system for prediction of diabetic eye morbidity.

Method: This research gives a prediction of diabetes retinopathy in diabetic patients using the Artificial Intelligence based expert system. This work divided in two parts, first part is examination of eye vision by the Ophthalmologist and also other examination such as PPBS, Hypotension, Cholesterol, duration of diabetes. Second part is 400 patients medical records are taken in 2019 year. And it is examined in the artificial expert system for prediction of diabetes retinopathy. It gives the accuracy, prediction, eye vision threatening, and morbidity in diabetic eye.

Result: The artificial intelligence expert system has 6 input parameters and in output one parameter which gives the prediction of diabetic neuropathy. The input parameters such as Post Prandial blood sugar, Hemoglobin Alc Test, duration of Diabetes, Hypotension, Cholesterol, and Vision in eyes. The output parameter was the morbidity in diabetic retinopathies which are Non proliferative, Proliferative, CMSE. This system gives accuracy, specificity, prediction of diabetic retinopathy.

Conclusion: This system is design for the endocrinologist and ophthalmologist to diagnosis diabetic retinopathy more quickly and prediction of eye morbidity.

\section{KEYWORDS : Artificial intelligence, Diabetic retinopathy, Fuzzy set theory, HbAlc test.}

\section{INTRODUCTION}

Artificial Intelligence is an emerging technology nowadays. It is used in every field such as mechanical, electrical, aerospace, and medical applications also. Fuzzy expert system formulates the reasoning process of human language by means of fuzzy logic and controls the presence of uncertainty for variety of problem domains[1]. Fuzzy logic gives a characteristic system to knowledge portrayal and inference from information bases which are inexact, inadequate, or not absolutely dependable[2]. The use of fuzzy logic concepts in the development of expert systems of medicine field increases enormously[2].

One of the biggest challenges currently experienced by healthcare organizations is the increasing burden of chronic diseases posing serious threats to public health in developing countries [3]. Diabetes is one of the world's most common and costly chronic diseases, and the number of patients suffering from diabetes has been showing an increasing trend in many countries[3]. Diabetes Mellitus (DM) is a serious chronic hormonal condition in which the body is unable to properly use the energy from food especially glucose or sugar[4]. Diabetes mellitus general symptoms are polydipsia, polyphagia, polyuria, weight loss, vision blurred, exhaustion, and an impaired healing. Diabetes mellitus has divided in few types, which are Type 1 Diabetes, Type 2 Diabetes, Prediabetes and Gestational Diabetes. It creates complications such as, heart diseases, stroke, neuropathy, retinopathy, deafness, foot damages; healing process slows down, fungal infections, depression, and dementia. Type-1 diabetes is also known as insulin dependent, it caused when the body stops producing insulin or produces too little insulin to regulate blood glucose level and typically recognized in childhood[4]. In Type-2 diabetes is also known as insulin resistance, it caused when the pancreas secretes insulin, but the body is unable to use the insulin[4]. Usually it is seen in adulthood, after age of 40 years. Gestational diabetes is high blood glucose level in pregnant women, when body can't meet the extra insulin demands during the pregnancy [4].
In 2015, World Health Organization surveys on 457 million people worldwide have diabetes[5]. In 2004, an estimated 3.4 million people died from the consequences of high fasting blood sugar [5]. In 2015, World Health Organization survey on Diabetic Retinopathy is the fifth leading cause of visual impairment and the fourth leading cause of blindness in the world, 285 million people worldwide are visually impaired[5]. In 2010 , diabetic retinopathy is the cause of visual impairment for 4.2 million people[5].

Author has do retrospective study in Rajkot city, Diabetes mellitus diseases are seen in 400 peoples, from that every 86 people have a Diabetic Retinopathy. In 2019, prevalence of Diabetes Retinopathy in Rajkot city is $22 \%$, it's a geographical statistical analysis.

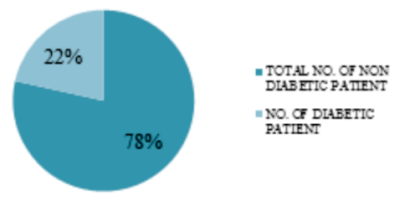

Figure 1: Prevalence of diabetes

Eye morbidity in diabetes mellitus is $45.30 \%$ in Rajkot city. Also percentage of CSME in diabetic patients is $16.20 \%$, NPDR (Non Proliferative diabetic retinopathy) is $34.80 \%$, and PDR (Proliferative diabetic retinopathy) is $10 \%$. Vision threatening in diabetic retinopathy is $26.75 \%$. Also percentage of vision threatening morbidity in Rajkot city is $5.75 \%$.

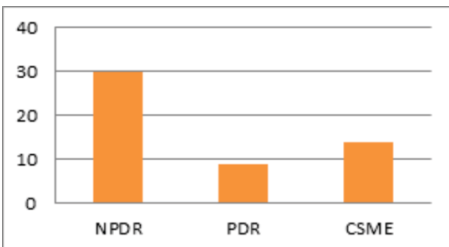

Figure 2: Eye morbidity in Diabetes 
DIABETES RETINOPATHY:

Eye is most important organ for human beings; it helps them to sense the color, shape and state of physical objects[6]. Diabetes Retinopathy is a complication of diabetes that causes damage to the blood vessels of the retina; the light sensitive tissue that lines the back part of the eye, which allowing seeing fine details[7]. Generally it is shown in working age people. As many people with type 1 diabetes suffer blindness as those with the more common type 2 diseases[7]. Sometimes diabetic patients don't observing the symptoms of diabetic retinopathy. May be it occurs in one or both eyes damages. Symptoms includes blurring in vision, difficulty in reading, floaters in vision, shadow in eyesight, eye pain, eye pressure, difficulty color perception.
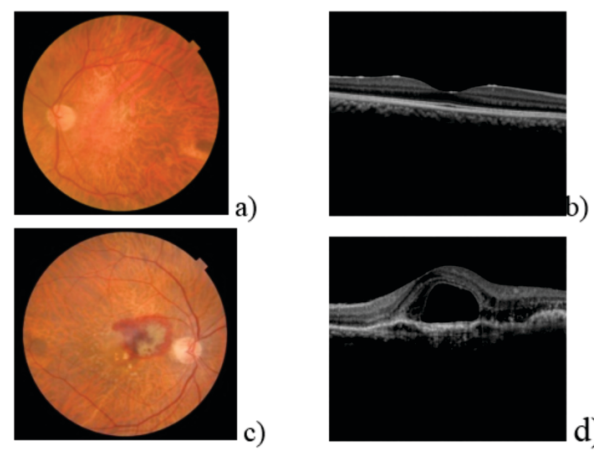

Figure 3: a) Normal b) NPDR c) PDR d) CSME

DR is classified in two types Non proliferative and proliferative. It terms for the lack or presence of abnormal new blood vessels coming from the retina. Non proliferative, eyes doesn't make new blood vessels during the first stages of DR. In the first stages, damaged in blood vessels frequently leak blood and fluid into the eye. Sometimes swell in the center of the retina or macula. NPDR have three stages mild, moderate, and severe and its fourth stage is known as proliferative retinopathy. Proliferative retinopathy, in which new blood vessels begin to grow within retina, but these new blood vessels are generally abnormal and grow in the center of the eye.

\section{PROPOSED METHOD:}

Fuzzy expert system is design for prediction of diabetes retinopathy based on the clinical examinations and ophthalmic test.

In the first phase, 400 people are diagnosed in the hospital from that 86 peoples are suffering from diabetes. These medical records were related to those patients who visited Swami Vivekananda Eye Care Hospital, Rajkot city, Gujarat during the year of 2019. this study is based on retrospective, inclusion criteria are middle aged patients between 40 to 70 years irrespective of gender, PPBS more than 140 and/or patients are on antidiabetic therapy; and exclusion criteria are juvenile diabetic mellitus, drug induce diabetes. Also some different clinical examinations are hypotension, cholesterol, duration of diabetes.

In the second phase, artificial intelligence expert system gives the prediction of diabetes retinopathy by giving some input parameters and trains fuzzy rules for making a output of the system.

Proper examination of diabetic eye should always begin by gathering during a history from the patient [medical student]. Ophthalmologist asks about any visual symptoms and risks for diabetes retinopathy such as pregnancy, hypertension, cholesterol levels, and retinal status, check their last hemoglobin Alc over the past 3 months. And eye examinations start from the visual acuity, intraocular pressure measurement, slit lamp exam, fundus exam and OCT exam.

The standard range of PPBS, normal is $140 \mathrm{mg} / \mathrm{DL}$, Prediabetes is $180 \mathrm{mg} / \mathrm{DL}$ and diabetes is $180 \mathrm{mg} / \mathrm{DL}$ and above. The HbAlc test is normal range is below $5.6 \%$, Prediabetes range is 5.7 to $6.4 \%$ and diabetes is $6.55 \%$ or above. The normal range of blood pressure is $120 \mathrm{mmHg} / 80 \mathrm{mmHg}$, hypotension generally range is low blood pressure less than $90 / 60 \mathrm{mmHg}$. Cholesterol level is normal level is $100 \mathrm{mg} / \mathrm{DL}$, LDL is less than $100 \mathrm{mg} / \mathrm{DL}$ and HDL is more than 200 to $400 \mathrm{mg} / \mathrm{DL}$.

\section{ARTIFICIAL INTELLIGENCE EXPERT SYSTEM:}

Author used fuzzy set theory as an artificial intelligence. Fuzzy set theory is the process of formulating the mapping from a given input to an output using fuzzy logic[6]. The process of fuzzy set theory involves membership functions, fuzzy logic operators, and "IF THEN" rules[6]. There are two types of fuzzy set theory that can be implemented in the fuzzy logic toolbox are Mamdani and Sugeno[6]. Fuzzy set theory applied in fields such as computer vision, automatic control, data classification, expert system, and decision analysis[6].

Fuzzy expert system steps are started from the first step is the fuzzification stage consists of collecting a crisp set of 6 input data and then converting it into a fuzzy set using fuzzy linguistic variables such as PPBS, $\mathrm{HbAlc}$, Duration of Diabetes, Hypotension, Cholesterol, Vision in eye; and then in fuzzy linguistic terms and in membership functions; then, an Mamdani inference system is executed according to a set of fuzzy rules; finally, the defuzzification steps converts the result fuzzy output into a crisp output using the membership functions; crisp output such as non-proliferative, Proliferative and CSME

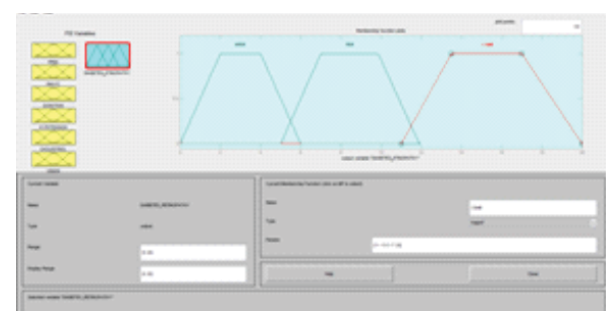

Figure 4: Membership function

PPBS which is $>140$ and $<140 \mathrm{mmHg}$, the prevalence of any retinopathy was $8 \%$ at 3 years, $25 \%$ at 5 years, $60 \%$ at 10 years, and $80 \%$ at 15 years. Hypertension and cholesterol is also responsible for the diabetic retinopathy. High blood pressure is responsible for the hypertension in patient. Cholesterol is responsible for blockage in blood vessels in retina or macula so that vision threatening in eye.

\section{TABLE 1}

Parameters of Input \& Output

\begin{tabular}{|c|c|c|c|}
\hline Sr. No. & $\begin{array}{c}\text { Input } \\
\text { Parameter }\end{array}$ & \begin{tabular}{|c|} 
Membership \\
Functions
\end{tabular} & Fuzzy Set Values \\
\hline \multirow[t]{3}{*}{1} & \multirow[t]{3}{*}{$\begin{array}{l}\text { Post Prandial } \\
\text { blood sugar }\end{array}$} & \multirow[t]{3}{*}{ Trapezoid } & $\begin{array}{l}\text { Normal [120 } 140160 \\
180]\end{array}$ \\
\hline & & & $\begin{array}{l}\text { Medium [170 } 199247 \\
\text { 280] }\end{array}$ \\
\hline & & & High [270 308360 400] \\
\hline \multirow[t]{3}{*}{2} & \multirow[t]{3}{*}{$\begin{array}{l}\text { Hemoglobin } \\
\text { Alc Test }\end{array}$} & \multirow[t]{3}{*}{ Trapezoid } & $\begin{array}{l}\text { Normal [3 3.71 } 4.39 \\
5.17]\end{array}$ \\
\hline & & & Medium [5 5.36 6 6.5] \\
\hline & & & High [6.29 6.27 7.47 8] \\
\hline \multirow[t]{3}{*}{3} & \multirow{3}{*}{$\begin{array}{l}\text { duration of } \\
\text { Diabetes }\end{array}$} & \multirow[t]{3}{*}{ Trapezoid } & Normal [2 344 5] \\
\hline & & & Medium [5 5.366 6.5] \\
\hline & & & High [6.29 6.27 7.47 8] \\
\hline
\end{tabular}




\begin{tabular}{|c|c|c|c|}
\hline \multirow[t]{3}{*}{4} & \multirow[t]{3}{*}{ Hypotension } & \multirow[t]{3}{*}{ Trapezoid } & $\left.\begin{array}{|lll}\text { Normal [120 } & 128 & 138 \\
145.3\end{array}\right]$ \\
\hline & & & $\begin{array}{l}\text { Medium [140 } 152164 \\
\text { 175] }\end{array}$ \\
\hline & & & $\begin{array}{l}\text { High [170178.5 } 189 \\
\text { 200] }\end{array}$ \\
\hline \multirow[t]{3}{*}{5} & \multirow[t]{3}{*}{ Cholesterol } & \multirow[t]{3}{*}{ Trapezoid } & 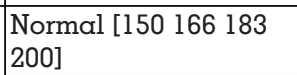 \\
\hline & & & \begin{tabular}{|l|} 
Medium [190 204225 \\
239]
\end{tabular} \\
\hline & & & High [230 252 282 300] \\
\hline \multirow[t]{3}{*}{6} & \multirow[t]{3}{*}{ Vision in eyes } & \multirow[t]{3}{*}{ Trapezoid } & Normal [2 $\left.3 \begin{array}{lll}2 & 4\end{array}\right]$ \\
\hline & & & Medium [4 6.268 l0] \\
\hline & & & 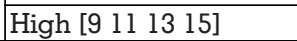 \\
\hline Sr.no. & $\begin{array}{c}\text { Output } \\
\text { Parameter }\end{array}$ & $\begin{array}{l}\text { Membership } \\
\text { Function }\end{array}$ & Fuzzy Set Values \\
\hline \multirow[t]{3}{*}{1} & \multirow{3}{*}{$\begin{array}{l}\text { Diabetic } \\
\text { Retinopathy }\end{array}$} & \multirow[t]{3}{*}{ Trapezoid } & NPDR [0 24 6] \\
\hline & & & PDR [5 79.85 9] \\
\hline & & & 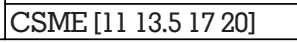 \\
\hline
\end{tabular}

The fuzzy rules for the prediction of diabetic retinopathy are:

- If PPBS is Normal, and HbAlc is Medium, and Duration of Diabetes is Normal, and Hypotension is Medium, and Cholesterol is Medium, and Vision is Normal, Then Diabetic retinopathy is NPDR.

- If the PPBS is Medium, and HbAlc is High, and Duration of Diabetes is High, and Hypotension is Medium, and Cholesterol is High and Vision is Medium, Then Diabetic Retinopathy is PDR.

- If PPBS is High, and HbAlc is High, and Duration of Diabetes is High, and Hypotension is High, and Cholesterol is High, and Vision is High, Then Diabetes Retinopathy is CSME.

\section{RESULT:}

The output this fuzzy set theory expert system is for prediction of diabetes retinopathy in Rajkot city patients. The prediction of visioning in eye is most important for patients who are suffering from diabetes, hypotension and cholesterol. In NPDR, most patients have diabetes, and cholesterol but duration of diabetes is not greater than the 8years. In PDR, patients are suffering from diabetes, cholesterol, hypotension and duration of diabetes is 10years. In PDR, less number of patients are seen. In CSME, vision in eye is lost by the patients fully.

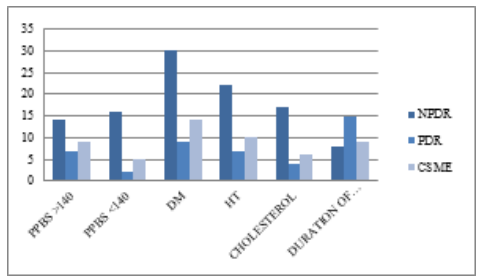

Figure 5: Results of prediction of DR

\section{CONCLUSIONS}

Author has made a artificial intelligence expert system for Prediction of diabetic retinopathy. From the examination of retina using the OCT, and other physical examinations performs for checking the morbidity in eye. More number of diabetes patients is suffering from the NPDR after 3 to 8years. In NPDR, PPBS, diabetes, cholesterol, hypotension and duration of diabetes, all are responsible. In PDR, duration of diabetes is 10years up so that it is less number of patients in Rajkot city. In CSME, the vision is fully lost, and diabetes is responsible for it.

\section{REFERENCES:}

[1] I. No and M. Kalpana, "Available Online at www.ijarcs.info Diagnosis of Diabetes using Correlation fuzzy logic in Fuzzy Expert System," vol. 3, no. 1, 2012

[2] I. K. Mujawar and B. T. Jadhav, "Web-based Fuzzy Expert System for Diabetes
Diagnosis," Int. J. Comput. Sci. Eng., vol. 7, no. 2, pp. 995-1000, 2019, doi 10.26438/ijcse/v7i2.9951000

[3] M. Rahmani Katigari, H. Ayatollahi, M. Malek, and M. Kamkar Haghighi, "Fuzzy expert system for diagnosing diabetic neuropathy," World J. Diabetes vol. 8, no. 2, p. 80, 2017, doi: 10.4239/wjd.v8.i2.80

[4] W: Www, R. P. Ambilwade, R. R. Manza, and R. Kaur, "International Journal of Emerging Technology and Advanced Engineering Prediction of Diabetes Mellitus and its Complications using Fuzzy Inference System," Certif. J., vol. 9001, no. 7, 2008

[5] World Health Organization, "TADDS: Tool for assessment of diabetes and diabetic retinopathy," 2015.

[6] M. Kamil, "Edge detection for Diabetic Retinopathy using fuzzy logic," Ijs, vol. 55, no. 3B, pp. 1395-1401, 2014.

[7] The Foundation of American Society of Retina Specialists, "The Foundation Diabetic Retinopathy : Diabetic retinopathy," no. 312, 2016.

[8] S. Arita, M. Yoneda, and Y. Hori, "Supporting System for the Diagnosis o Diabetes Mellitus Based on Glucose Tolerance Test Responses Using a Fuzzy Inference," Fuzzy Log., pp. 301-310, 1993, doi: 10.1007/978-94-01 1-2014-2 28.

[9] J. F. Bach, "Type l Diabetes," Autoimmune Dis., pp. 483-500, 2006, doi: 10.1016/B978-012595961-2/50039-1.

[10] M. Benamina, B. Atmani, and S. Benbelkacem, "Diabetes Diagnosis by CaseBased Reasoning and Fuzzy Logic," Int. J. Interact. Multimed. Artif. Intell., vol. 5, no. 3, p. 72, 2018, doi: 10.9781/ijimai.2018.02.001.

[11] M. Kalpana, "Fuzzy Expert System for Diabetes using Fuzzy Verdict Mechanism," Int. J. Adv. Netw. Appl., vol. 03, no. 02, pp. 1128-1134, 2011.

[12] R. B. Lukmanto, Suharjito, A. Nugroho, and H. Akbar, "Early detection of diabetes mellitus using feature selection and fuzzy support vector machine," Procedia Comput. Sci., vol. 157, pp. 46-54, 2019, doi: 10.1016/ j.procs.2019.08.140.

[13] E. G. Yildirim, A. Karahoca, and T. Uçar, "Dosage planning for diabetes patients using data mining methods," Procedia Comput. Sci., vol. 3, pp. 1374-1380, 2011, doi: 10.1016/j.procs.2011.01.018.

[14] R. A. Mohammadpour, S. M. Abedi, S. Bagheri, and A. Ghaemian, "Fuzzy Rule-Based Classification System for Assessing Coronary Artery Disease," Comput. Math. Methods Med., vol. 2015, 2015, doi: 10.1155/2015/564867.

[15] H. Jemal, Z. Kechaou, and M. Ben Ayed, "Enhanced decision support systems in intensive care unit based on intuitionistic fuzzy sets," Adv. Fuzzy Syst., vol. 2017, no. i, 2017, doi: 10.1155/2017/7371634.

[16] J. Oliver, Guidelines for the Prevention, Management and Care of Diabetes Mellitus, vol. 53, no. 9. 2013

[17] R. C. Chen, H. Q. Jiang, C. Y. Huang, and C. T. Bau, "Clinical Decision Support System for Diabetes Based on Ontology Reasoning and TOPSIS Analysis," J. Healthc. Eng., vol. 2017, pp. 9-12, 2017, doi: 10.1155/2017/4307508.

[18] C. S. Lee and M. H. Wang, "A fuzzy expert system for diabetes decision support application," IEEE Trans. Syst. Man, Cybern. Part B Cybern., vol. 4l, no. 1, pp. 139-153, 2011, doi: 10.1109/TSMCB.2010.2048899.

[19] H. Singh et al., "Real-life applications of fuzzy logic," Adv. Fuzzy Syst., vol. 2013, 2013, doi: 10.1155/2013/581879.

[20] D. Karahoca, A. Karahoca, and E. G. Yildirim, "Dosage planning for type 2 diabetes patients by ANFIS," Int. J. Mech. Eng. Technol., vol. 10, no. 2, pp. 798-808, 2019.

[21] S. Karabpour and A. Jafarian, "A New Artificial Intelligence Method for Prediction of Diabetes Type2," Bull. la Société R. des Sci. Liège, vol. 85, pp. 376-391, 2016.

[22] S. Lekkas and L. Mikhailov, "Evolving fuzzy medical diagnosis of Pima Indians diabetes and of dermatological diseases," Artif. Intell. Med., vol. 50 no. 2, pp. 117-126, 2010, doi: 10.1016/j.artmed.2010.05.007.

[23] S. Swati and P. Agarwal, "Diabetes Mellitus: An Ayurvedic View," J. Sci. Innov. Res., vol. 4, no. 4, pp. 193-196, 2015

[24] J. Mohmed, R. R. Palreddy, S. K. Gunda, D. J. Purohith, and M. Shaik, "Quinazolinone derivatives as growth hormone secretagogue recepto inhibitors: 3D-QSAR study," Int. J. ChemTech Res., vol. 9, no. 5, pp. 896-903, 2016, doi: 10.2337/dc10-S062

[25] H. W. Baynest, "Classification, Pathophysiology, Diagnosis and Management of Diabetes Mellitus," J. Diabetes Metab., vol. 06, no. 05, 2015, doi: 10.4172/2155-6156.1000541.

[26] L. B. O. Abdulfatai B. Olokoba, Olusegun A. Obateru, "Type 2 Diabetes: Review of Current Trends -," Int. J. Curr. Res. Rev., vol. 7, no. 18, pp. 61-66, 2015

[27] A. Rungta and T. Nadu, "A Review on Classification of Diabetes using Fuzzy Logic and Optimization Technique," vol. 13, no. 8, pp. 2143-2150, 2017.

[28] Z. Niswati, F. A. Mustika, and A. Paramita, "Fuzzy logic implementation for diagnosis of Diabetes Mellitus disease at Puskesmas in East Jakarta,"J. Phys. Conf. Ser., vol. 1114, no. 1, pp. 0-6, 2018, doi: 10.1088/17426596/1114/1/012107

[29] mr. Sumathy, P. Mythili, D. P. Kumar, T. M. Jishnujit, and K. R. Kumar, "Diagnosis of Diabetes Mellitus based on Risk Factors," Int. J. Comput. Appl., vol. 10, no. 4 pp. 1-4, 2010, doi: 10.5120/1473-1989.

[30] N. Chandgude and S. Pawar, "Diagnosis of diabetes using fuzzy inference system," Proc. - 2nd Int. Conf. Comput. Commun. Control Autom. ICCUBEA 2016, 2017, doi: 10.1109/ICCUBEA.2016.7860001.

[31] E. Taylor and J. H. Dobree, "Proliferative diabetic retinopathy. Site and size of initial lesions.," Br. J. Ophthalmol., vol. 54, no. 1, pp. 11-18, 1970, doi: 10.1136/bjo.54.1.11.

[32] P. K. Rani, R. Raman, A. Chandrakantan, S. S. Pal, G. M. Perumal, and T. Sharma, "Risk factors for diabetic retinopathy in self-reported rural population with diabetes," J. Postgrad. Med., vol. 55, no. 2, pp. 92-96, 2009 doi: 10.4103/0022-3859.48787.

[33] D. A. Antonetti et al., "Diabetic retinopathy: Seeing beyond glucose-induced microvascular disease," Diabetes, vol. 55, no. 9, pp. 2401-2411, 2006, doi: $10.2337 / \mathrm{db} 05-1635$

[34] F. He, X. Xia, X. F. Wu, X. Q. Yu, and F. X. Huang, "Diabetic retinopathy in predicting diabetic nephropathy in patients with type 2 diabetes and renal disease: A meta-analysis," Diabetologia, vol. 56, no. 3, pp. 457-466, 2013, doi: 10.1007/s00125-012-2796-6.

[35] R. L. Thomas, S. Halim, S. Gurudas, S. Sivaprasad, and D. R. Owens, "IDF Diabetes Atlas: A review of studies utilising retinal photography on the global 
prevalence of diabetes related retinopathy between 2015 and 2018," Diabetes Res. Clin. Pract., vol. 157, p. 107840, 2019, doi: 10.1016/j.diabres.2019.107840.

[36] V. Jain and S. Raheja, "Improving the Prediction Rate of Diabetes using Fuzzy Expert System," Int. J. Inf. Technol. Comput. Sci., vol. 7, no. 10, pp. 84-91, 2015, doi: $10.5815 /$ ijitcs.2015.10.10.

[37] N. Sarala and I. J. Firthouse, "An Analysis of Diabetes Using Fuzzy Soft," Int. J. Innov. Res. Sci. Eng. Technol., vol. 6, no. 3, pp. 3540-3548, 2017, doi: 10.15680/IJIRSET.2017.0603096.

[38] S. Sangam, A. Naveed, M. Athar, P. Prathyusha, S. Moulika, and S. Lakshmi, "International Journal of Health Sciences and Research," vol. 5, no. 1, pp. 156-164, 2015

[39] M. N. Piero, "Diabetes mellitus - a devastating metabolic disorder," Asian J. Biomed. Pharm. Sci., vol. 4, no. 40, pp. 1-7, 2015, doi: 10.15272/ ajbps. v4i40.645.

[40] K. Singh, D. Sharma, and S. Aggarwal, "A Real Time Patient Monitoring System based on Artificial Neural Fuzzy Inference System (ANFIS)," Int. J. Comput. Appl., vol. 146, no. 15, pp. 22-28, 2016, doi: 10.5120/ijca2016910959.

[41] Central Council For research in Ayurvedic Sciences, "Guidelines for prevention and management of Diabetes," no. 61, pp. 1-16.

[42] P. R. Orni, "A novel and superior approach to diabetic management utilization of a fuzzy-logic based system for precision insulin dosing in Type 2 diabetes patients," 2018.

[43] K. Papatheodorou, M. Banach, E. Bekiari, M. Rizzo, and M. Edmonds, "Complications of Diabetes 2017," J. Diabetes Res., vol. 2018, 2018, doi: 10.1155/2018/3086167.

[44] D. K. Jaiswal, "chapter 1: Introduction," pp. 1-56, 2010.

[45] A. Gordon, Z. Buch, V. Baute, and R. Coeytaux, "Use of Ayurveda in the Treatment of Type 2 Diabetes Mellitus," Glob. Adv. Heal. Med., vol. 8, p. 216495611986109, 2019, doi: 10.1177/2164956119861094.[1]-[10], [10]-[45] 